\title{
Doppler Echocardiographic Evaluation of Left Ventricular Output and Left Ventricular Diastolic Filling Changes in the First Day of Life
}

\author{
KENJI HARADA, TERUKAZU SHIOTA, YASUSHI TAKAHASHI, MASAMICHI TAMURA, \\ MANATOMO TOYONO, AND GORO TAKADA \\ Department of Pediatrics, Akita University School of Medicine, Akita, Japan
}

\begin{abstract}
The aim of this study was to evaluate the changes in Doppler transmitral flow patterns during the 1st d of life. Doppler echocardiography of the ascending aorta and mitral valve was performed serially in 20 normal neonates at 2, 12, and $24 \mathrm{~h}$ of age. A computer-interfaced digitizer pad was used to measure the following: ascending aorta flow velocity-time integral, total diastolic filling flow velocity-time integral, flow velocity-time integral of early diastolic filling, and flow velocity-time integral of atrial contraction. The inner diameter of the ductus arteriosus was $4.2 \pm 0.6 \mathrm{~mm}$ at $2 \mathrm{~h}$ of age, $2.3 \pm 0.5 \mathrm{~mm}$ at $12 \mathrm{~h}$ of age, and had closed in 17 of 20 neonates $(85 \%)$ by $24 \mathrm{~h}$ of age. The ascending aorta flow velocity-time integral and total diastolic filling flow velocity-time integral, which were high at $2 \mathrm{~h}$ of age, decreased significantly at $12 \mathrm{~h}$ of age $[12.2 \pm 2.1 \mathrm{~cm}$ versus $9.6 \pm 1.7 \mathrm{~cm}(p<0.001)$ and $8.0 \pm 1.1$ versus $7.1 \pm 1.4(p<0.01)$, respectively] but remained constant thereafter. Although no significant changes in flow velocity-time integral of atrial contraction and peak velocity of atrial contraction were noted during the first $24 \mathrm{~h}$ of birth, the flow velocity-time integral of early diastolic filling and peak velocity of early diastolic filling that were high at $2 \mathrm{~h}$ of age were reduced significantly at $12 \mathrm{~h}$ of age $[5.0 \pm 0.9 \mathrm{~cm}$ versus $4.1 \pm 1.1 \mathrm{~cm}(p$ $<0.005)$ and $60.9 \pm 9.0 \mathrm{~cm} / \mathrm{s}$ versus $50.3 \pm 9.0 \mathrm{~cm} / \mathrm{s}(p<$ $0.001)$, respectively], resulting in significant reductions in the ratio of flow velocity-time integral of early diastolic filling/flow velocity-time integral of atrial contraction and the ratio of peak velocity of early diastolic filling/peak velocity of atrial contraction at $12 \mathrm{~h}$ of age. The size of the ductus arteriosus was found to be correlated with the peak velocity of early diastolic filling $(r=0.42, p<0.05)$. Our results clearly demonstrate that the pattern of early diastolic filling was dependent on preload, whereas that of late diastolic filling was independent of preload in the early neonatal period. (Pediatr Res 35: 506-509, 1994)
\end{abstract}

\section{Abbreviations}

AO, ascending aorta

$\mathbf{E}$ area, flow velocity-time integral of early diastolic filling $A$ area, flow velocity-time integral of atrial contraction peak $E$, peak velocity of early diastolic filling

peak $A$, peak velocity of atrial contraction

$E / A$ area, ratio of $E$ area to $A$ area

peak $E / A$, ratio of peak $E$ to peak $A$

Received June 8, 1993; accepted November 11, 1993.

Correspondence: Kenji Harada, M.D., Department of Pediatrics, Akita University School of Medicine, 1-1-1 Hondo, Akita 010, Japan.
The loading condition of the left ventricle changes markedly during the transition from fetal to neonatal circulation and continues to be unstable shortly after birth. During this period, pulmonary blood flow, which acts as preload to the left ventricle, increases because of left-to-right ductus arteriosus shunting (1, 2). Among the hemodynamic factors affecting left ventricular diastolic filling, preload appears to play an important role, as has been recently suggested $(3,4)$. Interest has more recently been directed toward the possibility of using Doppler echocardiography to assess left ventricular diastolic hemodynamics in the early neonatal period (5-8). However, the impact of changes in preload on the transmitral flow pattern in neonates is as yet unclear. The purpose of our study was to evaluate by Doppler echocardiography the serial changes of left ventricular filling patterns in normal neonates during their transition to postnatal circulation.

\section{MATERIALS AND METHODS}

Study population. The study population consisted of 20 normal term neonates. Their mothers had uncomplicated pregnancies with no evidence of toxemia, diabetes mellitus, or pregnancyinduced hypertension. None of the infants were acutely ill or showed any evidence of congenital malformations. The mean birth weight was $3068 \pm 351 \mathrm{~g}$ (mean $\pm \mathrm{SD}$ ), and the mean gestational age was $39 \pm 1$ wk. Each mother received an explanation of the study and gave informed consent. Serial echocardiographic examinations were performed on each subject at 2 , 12 , and $24 \mathrm{~h}$ after birth.

Examination technique. A complete two-dimensional echocardiographic examination was performed on the subjects with an Aloka SSD 870 ultrasonoscope with a $5.0-\mathrm{MHz}$ transducer. The size of the Doppler sample volume was set at an axial length of $2 \mathrm{~mm}$, with a wall filter setting of $400 \mathrm{~Hz}$. All neonates were examined while they were lying quietly in the supine position breathing room air. To record the transmitral flow velocity profile, a standard apical two-chamber view was visualized, and the Doppler sample volume was placed in the inflow area of the left ventricle just below the level of the mitral annulus, adjusted to record the maximal flow velocities. The ascending aortic flow was measured from the suprasternal long axis view. The sample volume was placed in the AO immediately distal to the aortic valve. Care was taken to carry out these studies with the transducer beam as close to parallel to the presumed blood flow direction as possible. Because the angle between the estimated direction of blood flow and the Doppler beam was 20 degrees or less in the selected planes, no angle correction of the Doppler signal was made. All examinations were recorded at a paper speed of $100 \mathrm{~mm} / \mathrm{s}$. The electrocardiogram and respiration of each subject (with a pressure transducer placed against the $a b-$ dominal wall) were simultaneously recorded. With the aid of a computer-interfaced digitizer pad (Cardio 500, Kontron Medical System), the various Doppler flow indices were measured from 
the ascending aortic flow and transmitral flow and expressed in centimeters as the area under the flow velocity. These indices included the $E$ area and $A$ area, total diastolic filling flow velocity-time integral, peak $E$, and peak $A$ (Fig. 1). When the early and late diastolic waveforms overlapped, the $E$ and $A$ areas were calculated by dropping a vertical line to the baseline from the intersection of both waves. From these measurements, the $\mathrm{E} / \mathrm{A}$ area and the E/A were calculated.

Ductus arteriosus. The inner diameter and shunt pattern of the ductus arteriosus were serially obtained at the same time when the other hemodynamics were measured. The size of the ductus arteriosus was determined from the inner diameter on the two-dimensional color echocardiographic images. The inner diameter was measured at the narrowest portion of the ductal lumen in the parasternal long-axis plane. As suggested by Hiraishi et al. $(9,10)$, we also judged that the ductus arteriosus was closing when the narrowest diameter was less than $2 \mathrm{~mm}$ or nonphasic continuous low-velocity flow was recorded upstream of the narrowing portion of the ductus arteriosus. It was considered closed when the color image and shunt flow were no longer detectable.

Interobserver and intraobserver variability. To determine the interobserver and intraobserver variability of Doppler echocardiographic measurements, variables were analyzed in 10 randomly selected patients by two independent observers and by one observer on two different occasions. Both the variabilities were determined as the mean percent errors, derived from the absolute difference between two observations divided by the mean of the two observations and expressed in percentage. Data are presented as mean \pm SD.

Statistical analysis. All Doppler measurements reported here were averaged over five cardiac cycles at expiration and are presented as the mean \pm SD. The Tukey-Kramer multiple comparison procedure was used to evaluate the differences in a set of measurements from 2 to $24 \mathrm{~h}$ after birth. Spearman's correlation coefficients were calculated to relate the size of the ductus arteriosus and indices of left ventricular diastolic filling. Results with $p<0.05$ were considered to be statistically significant.

\section{RESULTS}

Interobserver and intraobserver variability of Doppler flow measurements. Interobserver variabilities for AO flow velocitytime integral, total diastolic filling flow velocity-time integral, E area, $\mathrm{A}$ area, and $\mathrm{E} / \mathrm{A}$ area were as follows (ranges in parentheses): $3.1 \pm 1.4 \%(1.3-5.3 \%), 2.8 \pm 2 \%(0.7-7.9 \%), 2.7 \pm 1.9 \%(1.1-$ $7.1 \%), 7.8 \pm 7.4 \%(1.2-21.7 \%)$, and $8.0 \pm 4.7 \%(0.4-19.8 \%)$, respectively. Intraobserver variabilities for these variables were $1.8 \pm 1.4 \%(0.1-3.3 \%), 2.3 \pm 2.0 \%(0-7.8 \%), 2.7 \pm 2.4 \%(0-$ $11.5 \%), 7.0 \pm 4.7 \%(0-17.1 \%)$, and $8.0 \pm 4.7 \%(0.6-18.2 \%)$, respectively.

The results of measurements of the Doppler flow indices in normal neonates are summarized in Table 1.

Heart rate. The mean heart rates of the $\mathrm{AO}$ and mitral valve did not show any statistically significant changes from 2 to $24 \mathrm{~h}$ of age.

Flow velocity-time integral and transmitral flow velocity. The AO flow velocity-time integral and total diastolic filling flow velocity-time integral decreased significantly at $12 \mathrm{~h}$ of age compared with the values at $2 \mathrm{~h}$ of age [9.6 \pm 1.7 versus $12.2 \pm$ $2.1 \mathrm{~cm}(p<0.001)$ and $7.1 \pm 1.5$ versus $8.0 \pm 1.1 \mathrm{~cm}(p<0.01)$, respectively], with no significant differences between the values at 12 and $24 \mathrm{~h}$. The E area and peak E at $12 \mathrm{~h}$ decreased significantly compared with the values at $2 \mathrm{~h}[4.1 \pm 1.1 \mathrm{~cm}$ versus $5.0 \pm 0.90 \mathrm{~cm}(p<0.005)$, and $50.3 \pm 9.0 \mathrm{~cm} / \mathrm{s} \pm 60.9$ $\pm 9.0 \mathrm{~cm} / \mathrm{s}(p<0.001)$, respectively], but there were no significant differences between the two values at 12 and $24 \mathrm{~h}$ after birth. The $A$ area and peak $A$ remained virtually unchanged from 2 to $24 \mathrm{~h}$ and thus resulted in significant reductions in the $\mathrm{E} / \mathrm{A}$ area and peak E/A at $12 \mathrm{~h}$ compared with the values at $2 \mathrm{~h}$ $[1.40 \pm 0.26$ versus $1.67 \pm 0.41(p<0.005)$ and $1.14 \pm 0.14$ versus $1.28 \pm 0.25(p<0.05)$, respectively].

Size of ductus arteriosus. The inner diameter of the ductus arteriosus was $4.2 \pm 0.6 \mathrm{~mm}$ at $2 \mathrm{~h}, 2.3 \pm 0.5 \mathrm{~mm}$ at $12 \mathrm{~h}$, and was closing in three neonates and had closed in 17 of 20 neonates $(85 \%)$ by $24 \mathrm{~h}$ of age.

Relationship between size of ductus arteriosus and indices of left ventricular diastolic filling. Weak correlations were seen with peak $\mathrm{E}(r=0.42, p<0.05)$ and peak E/A $(r=0.32, p<0.05)$.

\section{DISCUSSION}

Among the hemodynamic factors affecting left ventricular diastolic filling, preload appears to play an important role, as disclosed by recent experimental studies $(11,12)$. Few studies, however, have shown the effects of preload reduction on Doppler transmitral velocity patterns in human beings $(3,4)$. By using nonpharmacologic intervention to decrease preload in normal subjects, Triulzi et al. (3) observed decreases in the peak velocity and velocity-time integral of the $E$ wave without changes in the same values of the $A$ wave. Similar results were obtained by others using nitroglycerin for preload reduction (13, 14). Experimental studies $(11,12)$ have demonstrated that the instanta-

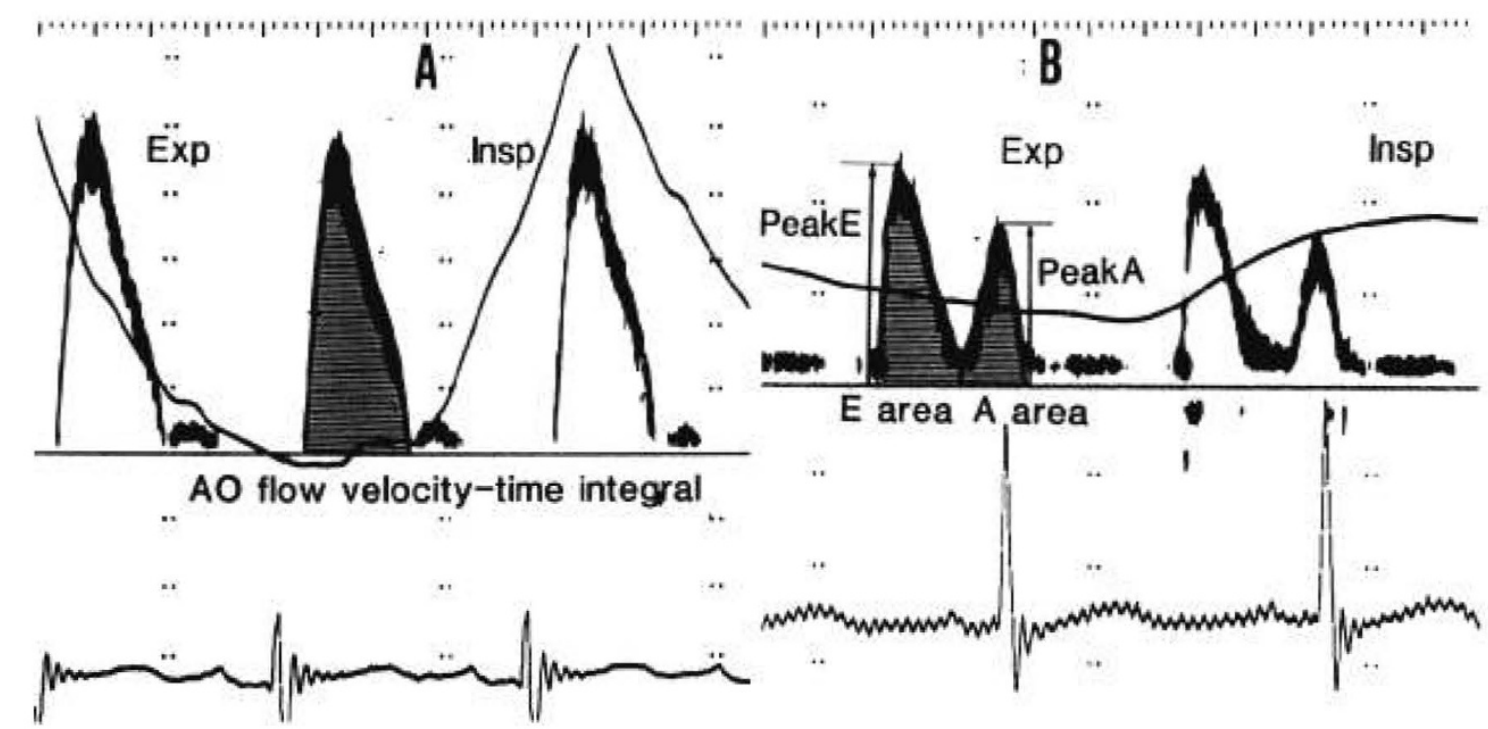

Fig. 1. Doppler flow velocity measurements. $A$, Ascending aortic flow velocity profile. $B$, Transmitral flow velocity profile. Exp, expiration; Insp, inspiration. 
Table 1. Echocardiographic measurements*

\begin{tabular}{|c|c|c|c|}
\hline & \multicolumn{3}{|c|}{ Age (h) } \\
\hline & 2 & 12 & 24 \\
\hline AO HR (beats/min) & $130 \pm 16$ & $126 \pm 13$ & $123 \pm 18$ \\
\hline MV HR (beats/min) & $125 \pm 9$ & $121 \pm 7$ & $121 \pm 10$ \\
\hline Total transmitral flow velocity-time integral $(\mathrm{cm})$ & $8.02 \pm 1.07$ & $7.09 \pm 1.43 \ddagger$ & $7.22 \pm 1.10 \S$ \\
\hline $\mathrm{E}$ area $(\mathrm{cm})$ & $4.97 \pm 0.85$ & $4.13 \pm 1.12 \|$ & $4.24 \pm 0.83 \ddagger$ \\
\hline Peak E (cm/s) & $60.9 \pm 9.0$ & $50.3 \pm 9.0 \dagger$ & $53.4 \pm 8.4 \|$ \\
\hline Peak A $(\mathrm{cm} / \mathrm{s})$ & $46.2 \pm 5.2$ & $43.9 \pm 5.2$ & $44.8 \pm 4.7$ \\
\hline Peak E/A & $1.28 \pm 0.25$ & $1.14 \pm 0.14 \ddagger$ & $1.19 \pm 0.14 \S$ \\
\hline
\end{tabular}

\footnotetext{
* HR, heart rate; $M V$, mitral valve.

$+p<0.001$ compared with $2 \mathrm{~h}$ of age.

$\ddagger p<0.01$ compared with $2 \mathrm{~h}$ of age.

$\S p<0.05$ compared with $2 \mathrm{~h}$ of age.

$\| p<0.005$ compared with $2 \mathrm{~h}$ of age.
}

neous peak velocities of transmitral flow depend strictly on the atrioventricular pressure gradients and therefore on the left atrial pressure, which in turn is affected mainly by preload. However, to our knowledge, our report is the first serial evaluation of the relationship between left ventricular output changes and left ventricular diastolic filling changes in normal human subjects within the 1 st $\mathrm{d}$ of life.

Serial left ventricular output changes. In our study, as in a previous study (15), the AO flow velocity-time integral was calculated as an indicator of left ventricular output. Volumetric flow in a great artery is equal to the product of the flow velocity integral and the cross-sectional area of the artery. However, because of technical limitations and inherent errors in measuring the diameter of such arteries (16), we assumed that the crosssectional area of each artery remained constant between 2 and $24 \mathrm{~h}$ after birth so that any measured changes in the AO flow velocity-time integral would be reflective of changes in stroke volume. The AO flow velocity-time integral has been shown to correlate closely with invasively measured stroke volume in animals $(17,18)$ and in adult patients (19). In our study, and in that of Agata et al. (2), the AO flow velocity-time integral was at the highest level at $2 \mathrm{~h}$ of age. As previously documented (9, 20), our study has shown that the ductus arteriosus remained widely patent shortly after birth with a predominant left-to-right shunting. This shunt is likely to play a major role in the increased $\mathrm{AO}$ flow velocity-time integral at $2 \mathrm{~h}$ of age. At $12 \mathrm{~h}$ of age, the AO flow velocity-time integral declined markedly to $80 \%$ of that at $2 \mathrm{~h}$. Most of our subjects had a small ductus arteriosus, either with a mean inner diameter of $2.3 \mathrm{~mm}$ or in the process of closing at $12 \mathrm{~h}$ of age. Although it is difficult to quantitate the amount of left-to-right shunt flow volume from the size of the ductus arteriosus, the present sequential data suggest that the left-to-right shunt was reduced markedly by $12 \mathrm{~h}$ of age. Our result of serial changes in the $\mathrm{AO}$ flow velocity-time integral is firmly supported by the data of Drayton and Skidmore (1), in which a left-to-right shunt of $62 \mathrm{~mL} / \mathrm{kg} / \mathrm{min}$ shortly after birth declined rapidly to $14 \mathrm{~mL} / \mathrm{kg} / \mathrm{min}$ during the first $12 \mathrm{~h}$ of age. The AO flow velocity-time integral dropped to $75 \%$ of the 2 -h value by $24 \mathrm{~h}$ of age and did not show significant changes between 12 and $24 \mathrm{~h}$ of age. Therefore, from our study, we consider that the decline in preload on the left ventricle occurred during the first $12 \mathrm{~h}$ after birth.

Serial left ventricular diastolic filling changes. Only a few reports have been published on serial left ventricular diastolic filling changes in the early neonatal period. In addition, little is known about the impact of changes in preload on the transmitral flow pattern in neonates. In our study, the total diastolic filling flow velocity-time integral, peak $\mathrm{E}$, and $\mathrm{E}$ area were at the highest level at $\mathbf{2} \mathrm{h}$ of age, as was the AO flow velocity-time integral.
These indices at $12 \mathrm{~h}$ of age declined significantly, with no change in the peak $A$ and $A$ area, causing significant reductions in the $\mathrm{E} / \mathrm{A}$ velocity and $\mathrm{E} / \mathrm{A}$ area. It is likely that the decline in the total diastolic filling flow velocity-time integral, peak $\mathrm{E}$, and $\mathrm{E}$ area at $12 \mathrm{~h}$ of age may reflect the decreased left ventricular preload caused by a reduction in left-to-right shunt flow volume through a patent ductus arteriosus. Additionally, we have demonstrated that the size of the ductus arteriosus correlated well with peak E and peak E/A, suggesting that early diastolic filling is dependent on preload, whereas atrial filling is independent of preload in the early neonatal period.

After birth, the left atrial pressure increased in accordance with the increase in pulmonary venous return caused by a patent ductus arteriosus. Therefore, the major determinant of the reduced Doppler flow velocity during rapid filling at $12 \mathrm{~h}$ of age is attributable to the diminished atrial pressure caused by a decreased preload by the closing process of the ductus arteriosus. Triulzi et al. (3) speculated that the peak velocity and the integral of the $\mathrm{A}$ wave did not change because, despite a reduction in preload, the atrioventricular pressure gradient and the amount of ventricular filling in late diastole were kept constant by a parallel afterload reduction to atrial contraction. We can therefore conclude that any interpretation of the transmitral velocity pattern in terms of diastolic function should take into account the redistribution in transmitral flow induced by preload conditions.

\section{REFERENCES}

1. Drayton MR, Skidmore R 1987 Ductus arteriosus blood flow during first 48 hours of life. Arch Dis Child 62:1030-1034

2. Agata Y, Hiraishi S, Oguchi K, Misawa H, Horiguchi Y, Fujino N, Yashiro K, Shimada N 1991 Changes in left ventricular output from fetal to early neonatal life. J Pediatr 119:441-445

3. Triulzi MO, Castini D, Ornaghi M, Vitolo E 1990 Effects of preload reduction on mitral flow velocity pattern in normal subjects. Am J Cardiol 66:9951001

4. Castini D, Mangiarotti E, Vitolo E, Conconi B, Triulzi MO 1992 Effects of venous return reduction in hypertensive patients: is there a Doppler diastolic dysfunction index independent of preload reduction? Am Heart J 123:12991306

5. Grenadier E, Lima CO, Allen HD, Sahn DJ, Barron JV, Valdex-Cruz LM Goldberg SJ 1984 Normal intracardiac and great vessel Doppler flow velocities in infants and children. J Am Coll Cardiol 4:343-350

6. Wilson N, Reed K, Allen HD, Marx GR, Goldberg SJ 1987 Doppler echocardiography observations of pulmonary and transvalvular velocity changes after birth and during the early neonatal period. Am Heart J 113:750-758

7. Johnson GL, Moffett CB, Noonan JA 1988 Doppler echocardiographic studies of diastolic ventricular filling patterns in premature infants. Am Heart $J$ 116:1568-1574

8. Riggs TW, Rodriguez R, Snider AR, Batton D, Pollock J, Sharp EJ 1989 Doppler echocardiographic evaluation of right and left ventricular diastolic function in normal neonates. J Am Coll Cardiol 13:700-705

9. Hiraishi S, Misawa H, Oguchi K, Kadoi N, Saito K, Fujino N, Hojo M, Horiguchi Y, Yashiro K 1987 Two-dimentional Doppler echocardiographic 
assessment of closure of the ductus arteriosus in normal newborn infants. J Pediatr 111:755-760

10. Hiraishi S, Horiguchi Y, Misawa H, Oguchi K, Kadoi N, Fujino N, Yashiro K 1987 Noninvasive Doppler echocardiographic evaluation of shunt flow dynamics of the ductus arteriosus. Circulation 75:1146-1153

11. Ishida Y, Meisner JS, Tsujioka K, Gallo JI, Yoran C, Frater RWM, Yellin EL 1986 Left ventricular filling dynamics: influence of left ventricular relaxation and left atrial pressure. Circulation 74:187-196

12. Choong CY, Abascal VM, Thomas JD, Guerrero JL, McGlew S, Weyman AE 1988 Combined influence of ventricular loading and relaxation on the transmitral flow velocity profile in dogs measured by Doppler echocardiog raphy. Circulation 78:672-683

13. Choong CY, Herrmann HC, Weyman AE, Fifer MA 1987 Preload dependence of Doppler-derived indexes of left ventricular diastolic function in humans. J Am Coll Cardiol 10:800-808

14. Vandemberg BF, Rumberger JA, Kerber RE 1988 Influence of sublingua nitroglycerin on diastolic transmitral flow velocities in normal subjects. Am J Cardiol 61:481-482
15. Takenaka K, Waffarn F, Dabestani A, Gardin JM, Henry WL 1987 A pulsed Doppler echocardiographic study of the postnatal changes in pulmonary artery and ascending aortic flow in normal term newborn infants. Am Heart J 113:759-766

16. Goldberg SJ, Sahn DJ, Allen HD, Valdes-Cruz LM, Hoenecke H, Carnahan Y 1982 Evaluation of pulmonary and systemic blood flow by 2-dimensional Doppler echocardiography using fast Fourier transform spectral analysis. Am J Cardiol 50:1394-1400

17. Colocousis JS, Huntsman LL, Curreri PW 1977 Estimation of stroke volume changes by ultrasonic Doppler. Circulation 56:914-917

18. Steingart RM, Meller J, Barovick J, Patterson R, Herman MV, Teichholz LE 1980 Doppler echocardiographic measurement of beat-to-beat changes in stroke volume in dogs. Circulation 62:542-548

19. Elkayam U, Gardin JM, Berkley R, Hughes CA, Henry WL 1983 The use of Doppler flow velocity measurement to assess the hemodynamic response to vasodilators in patients with heart failure. Circulation 67:377-383

20. Huta JC, Cohen M, Gutgesell HP 1984 Patency of the ductus arteriosus in normal neonates: two-dimensional echocardiography versus Doppler assessment. J Am Coll Cardiol 4:561-564 